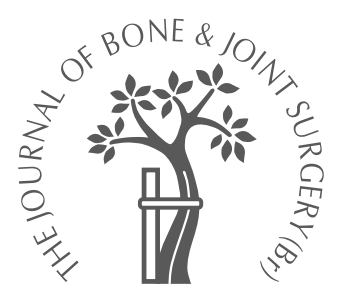

D. Jafari,

B. Sharifi

From Shafa

Rehabilitation

Hospital, Tehran, Iran
D. Jafari, MD, Orthopaedic Hand Surgeon, Assistant Professor

B. Sharifi, Orthopaedic Chief Resident

Shafa Rehabilitation Hospital, Mojahedin Islam Avenue, Tehran 1157637131 Iran.

Correspondence should be sent to Dr D. Jafari.

(C)2005 British Editorial Society of Bone and Joint Surgery

doi:10.1302/0301-620X.87B1. $15453 \$ 2.00$

$J$ Bone Joint Surg $[\mathrm{Br}]$ 2005;87-B:108-10.

Received 8 March 2004;

Accepted 19 April 2004

\title{
A variant of mirror hand
}

\author{
A CASE REPORT
}

We describe a rare variant of mirror hand in a 20 -year-old man who presented with multiple fingers. Radiographs revealed two ulnae (one vestigial) and a radius. There was duplication of the humeral head. The unique features of this case are the age of patient before the start of treatment and extension of the duplication proximal to the elbow.

Mirror hand (ulnar dimelia) is an exceedingly rare congenital anomaly of the upper limb. Characteristically there is duplication of the ulna, an absent radius, and multiple fingers which are symmetrical around the midline. Over the years, there have been several case reports in the literature and some variations of the deformity have been described.

Multiple fingers with one ulna and one hypoplastic radius, ${ }^{1}$ multiple fingers with two ulnae (one vestigial) and one radius, ${ }^{2}$ and complete duplication of the hand including the thumb with a distinct radius and ulna in the forearm ${ }^{3}$ have been described.

We describe another variant of ulnar dimelia in which there is incomplete fusion of two ulnae (one vestigial), one radius and multiple fingers and an extension of duplication proximal to elbow joint with duplication of the proximal humerus.

\section{Case report}

A 20-year-old Afghan man presented with a congenital abnormality of the right upper limb. He was the fourth child of a nonconsanguineous marriage by full-term vaginal delivery. There was no family history of congenital anomalies. He had no other abnormalities. He was left handed and worked as a labourer.

Flexion of the shoulder was to $60^{\circ}$ and abduction to $45^{\circ}$. On internal rotation his hand reached his sacrum and external rotation was to $70^{\circ}$. The elbow had a fixed flexion deformity of $30^{\circ}$ and further flexion of $120^{\circ}$ was possible (Fig. 1). The upper arms were equal in length. The forearm on the affected side was short in comparison with the normal left forearm (Fig. 2). The wrist had a fixed flexion deformity of $30^{\circ}$ and further flexion of $50^{\circ}$ was possible. There was a fixed pronation deformity with no active rotation of the forearm. The hand had eight well-formed digits arranged symmetrically as mirror images on either side of a presumptive sagittal axis (Fig. 3).

Radiographs showed a duplicated humeral head (Fig. 4). The distal humerus was almost normal in appearance except for hypoplasia of the capitellum. There were two ulnae, one of which was vestigial. They were fused in their distal two thirds but separated into two ulnar heads. There was a single olecranon (Fig. 5). There was a single radius with well defined proximal and distal ends. All eight digits had the usual triphalangeal appearance with the metacarpals having their growth plates at the distal ends (Fig. 6). Prior to surgery angiography was undertaken but the findings did not alter the nature of the surgical treatment.

Operative technique. The most medial and second and third lateral fingers were amputated and filletted skin flaps were preserved. The medial finger was amputated at the level of the carpometacarpal joint and the second and third lateral fingers were amputated at the metacarpal base. The most lateral finger was pollicised (Fig. 7). A long arm thumb spica was applied. It was removed after five days. The wounds were cleaned and a short arm thumb spica was applied. He did not return for follow-up examination and we suspect that he returned to Afghanistan.

\section{Discussion}

There are few descriptions of mirror hand in the literature. There may be complete duplication of the hand including the thumb with a normal radius and ulna. ${ }^{3}$ King and Hoyes ${ }^{4}$ described a case with eight digits in the hand and a forearm with an ulna and a distinguish- 


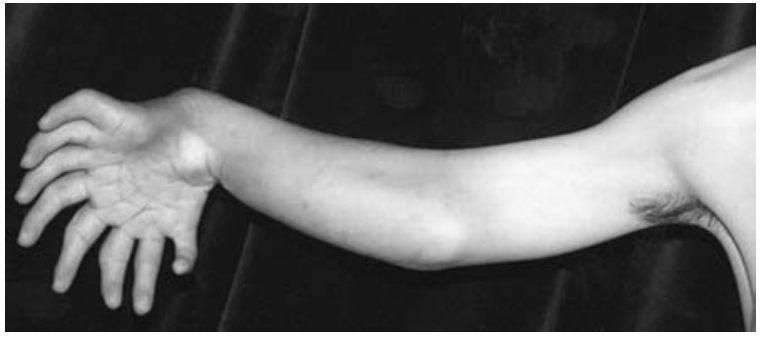

Fig. 1

Clinical photograph of the whole right arm.

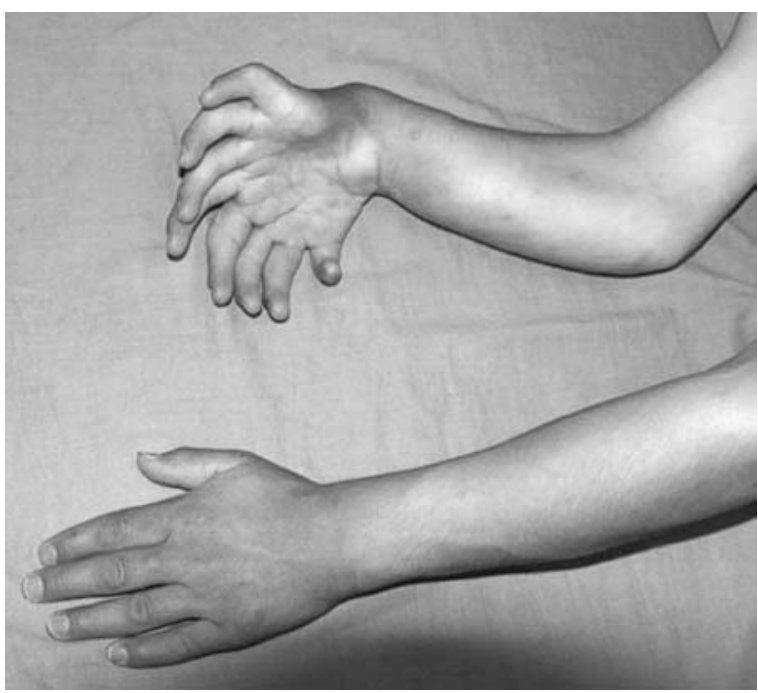

Fig. 2

Clinical photograph showing a comparison of the upper arms.

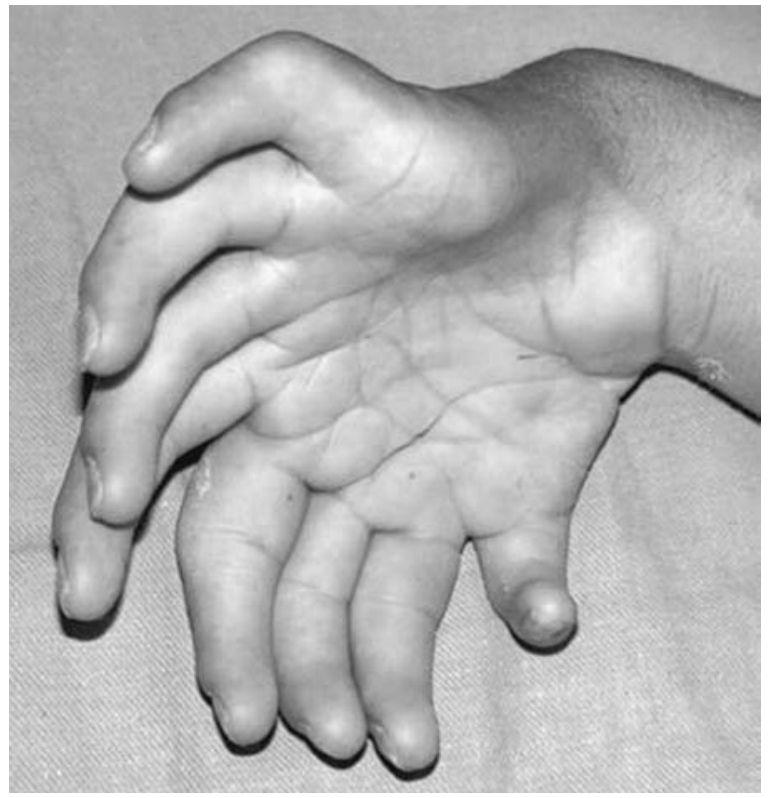

Fig. 3

Clinical photograph of the right hand with eight well-formed digits.

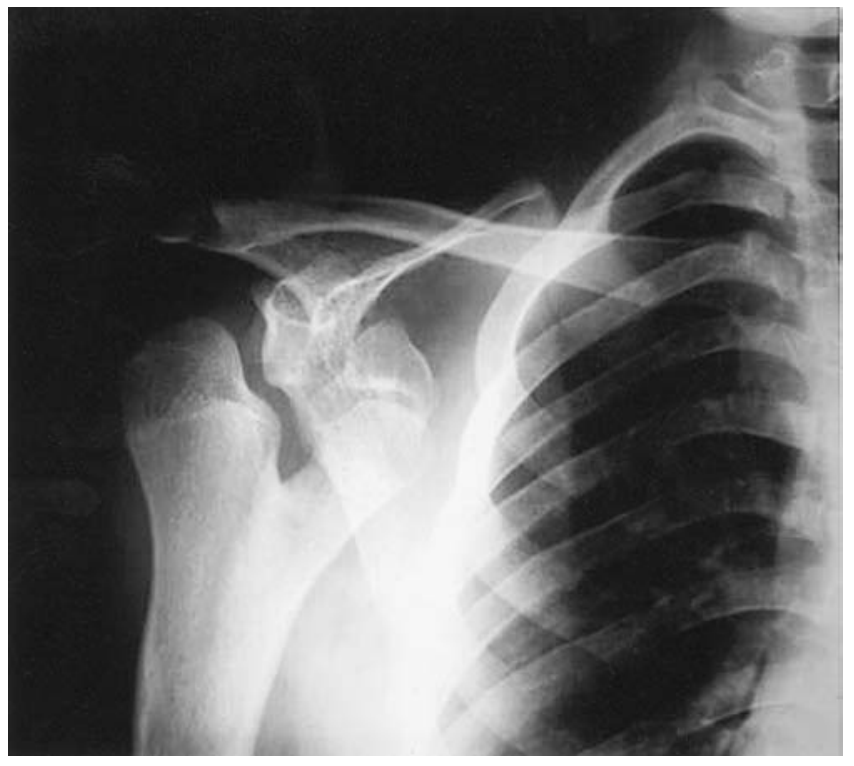

Fig. 4

AP radiograph of right shoulder showing duplication of the humeral head.

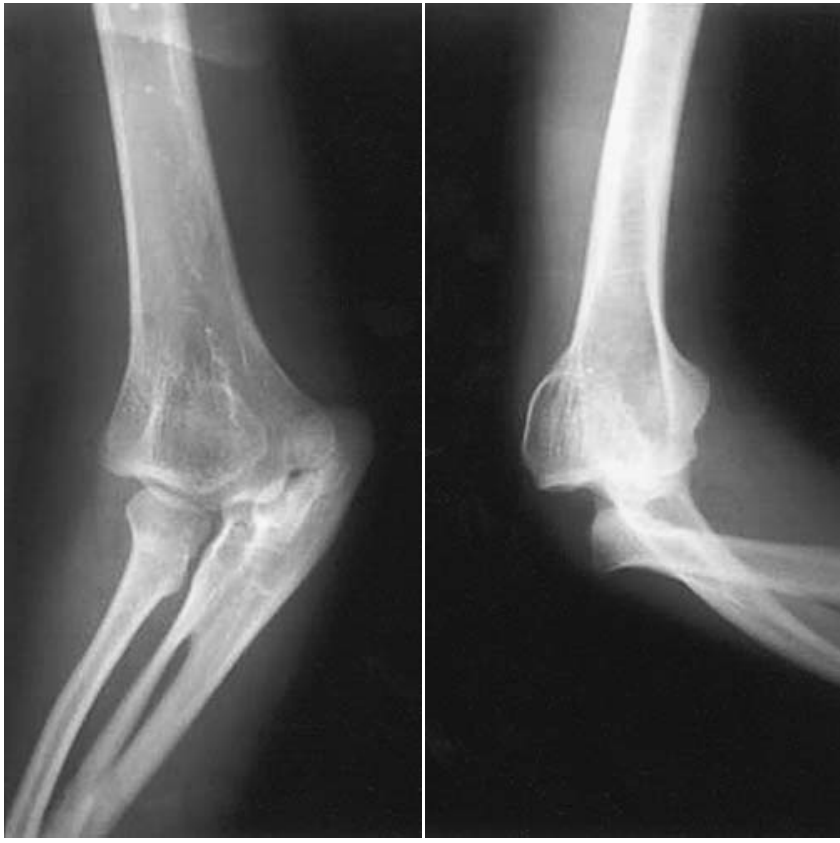

Fig. 5

$\mathrm{AP}$ and lateral radiograph of right elbow. 


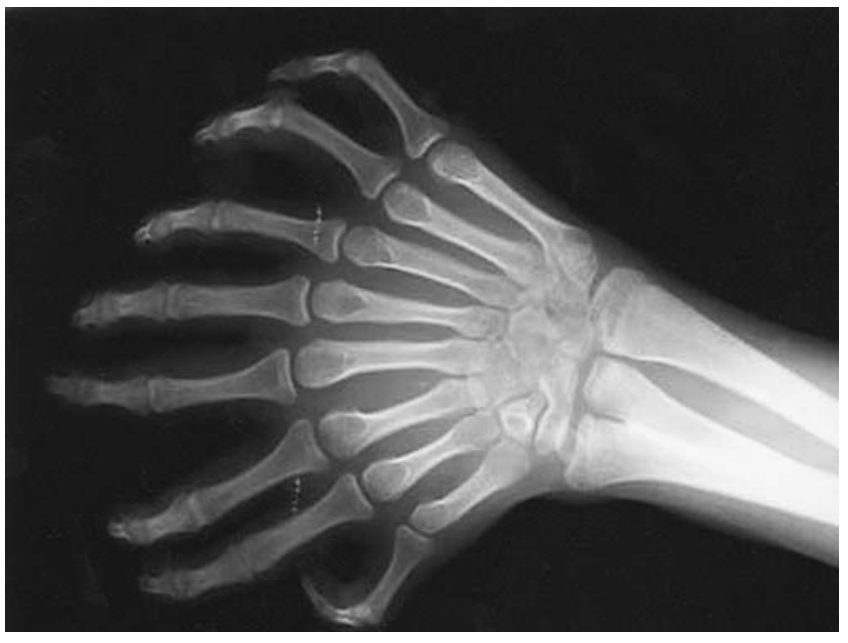

Fig. 6

AP radiograph of the right hand.

able radius. Yang et $\mathrm{al}^{5}$ reported a case with multiple fingers but with a distinct radius and ulna. Barton et $\mathrm{al}^{2}$ described a variant with multiple fingers, two ulnae (one vestigial) and a radius. These variants are probably intermediate between the classic ulnar dimelia and multiple deformities of the hand as the duplication of the hand is incomplete.

In a review of the literature, we did not find a report of a mirror hand where duplication extended proximal to the elbow joint and where the patient had not been treated before adulthood.

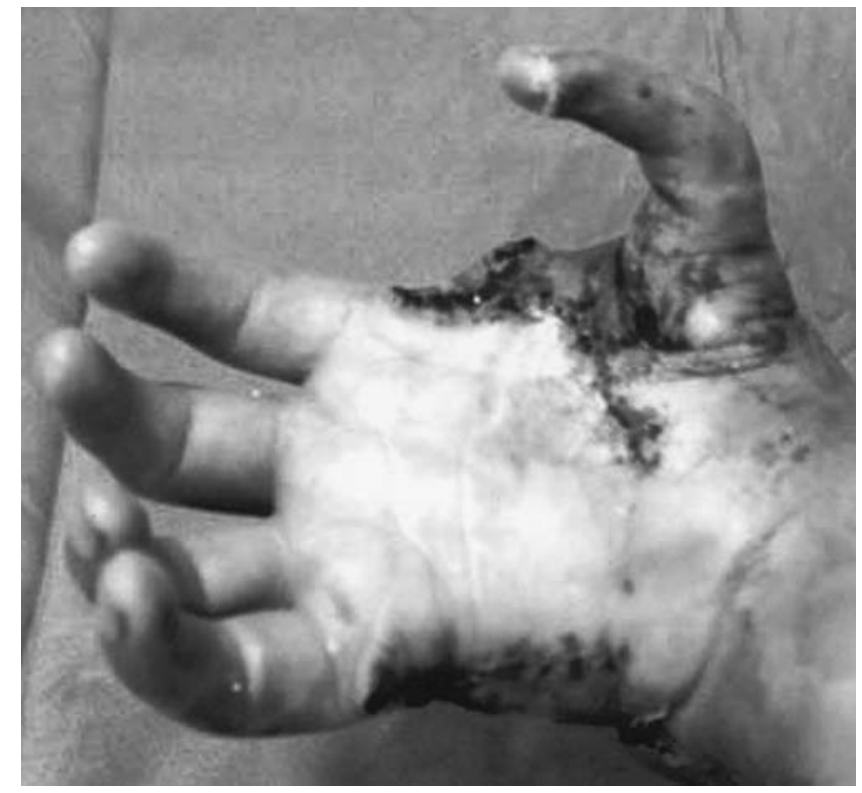

Fig. 7

Clinical post-operative photograph of the right hand.

No benefits in any form have been received or will be received from a commercial party related directly or indirectly to the subject of this article.

\section{References}

1. Al-Qattan MM, Al-Thunayan A, De Cordiere M, Nandagopal N, Pitkanen J. Classification of the mirror hand-multiple hand spectrum. J Hand Surg [Br] 1998;23-B:534-6.

2. Barton NJ, Buck-Gramcko D, Evans DM. Soft-tissue anatomy of mirror hand. $J$ Hand Surg [Br] 1986;11-B:307-9.

3. Kelikian H. Multiple and mirror hand. In: Kelikian H, ed. Congenital deformities of the hand and forearm. Philadelphia: WB Saunders, 1974:457-66.

4. King RJ, Hoyes AD. The mirror hand abnormality. Hand 1982;14:188-93.

5. Yang SS, Jackson L, Green DW, Weiland AJ. A rare variant of mirror hand: a case report. J Hand Surg [Am] 1996;21-A:1048-51. 